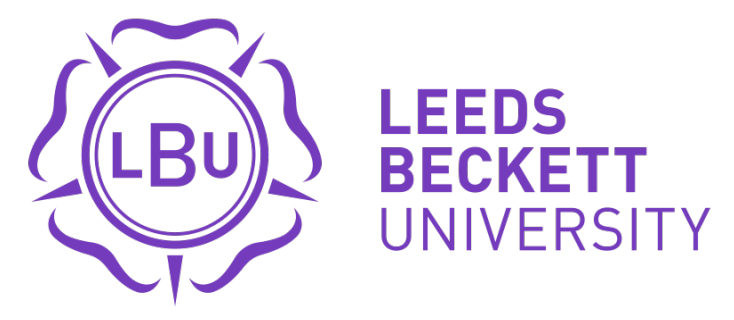

Citation:

Roe, SL (2017) Chasing ambiguity: critical reflections on working with dance graduates. Research in Dance Education, 18 (2). pp. 205-216. ISSN 1464-7893 DOI: https://doi.org/10.1080/14647893.2017.1354842

Link to Leeds Beckett Repository record:

https://eprints.leedsbeckett.ac.uk/id/eprint/4493/

Document Version:

Article (Accepted Version)

This is an Accepted Manuscript of an article published by Taylor \& Francis in Research in Dance Education on 25 October 2017, available online: http://www.tandfonline.com/10.1080/14647893.2017.1354842

The aim of the Leeds Beckett Repository is to provide open access to our research, as required by funder policies and permitted by publishers and copyright law.

The Leeds Beckett repository holds a wide range of publications, each of which has been checked for copyright and the relevant embargo period has been applied by the Research Services team.

We operate on a standard take-down policy. If you are the author or publisher of an output and you would like it removed from the repository, please contact us and we will investigate on a case-by-case basis.

Each thesis in the repository has been cleared where necessary by the author for third party copyright. If you would like a thesis to be removed from the repository or believe there is an issue with copyright, please contact us on openaccess@leedsbeckett.ac.uk and we will investigate on a case-by-case basis. 


\title{
Chasing Ambiguity: Critical Reflections On Working With Dance Graduates
}

\author{
Sarah Roe
}

School of Film, Music, and Performing Arts, Leeds Beckett University, Leeds, UK

s.1.roe@leedsbeckett.ac.uk

Leeds Beckett University, Priestley Room 226, Headingley Campus, Church Wood Avenue, Leeds, West Yorkshire, LS6 3QS 


\title{
Chasing Ambiguity: Critical Reflections On Working With Dance Graduates
}

\begin{abstract}
If, as Shreeve, Sims, and Trowler $(2010,125)$ discuss arts education should be concerned with 'uncertainty and open-endedness', I ask the question, are we able to foster this alongside current institutional demands and embedded pedagogies within higher education environments? If not, then what effect does this have on current dance graduates? I attend to these questions through critical reflections upon my work as a pedagogue, specifically reflecting upon a series of artistic choreographic projects working in collaboration with recent dance graduates. During these choreographic projects my interactions with the graduates illuminated their struggle to operate within ambiguous creative spaces outside of institutional environments. This struggle manifested in turbulent working relationships and highlighted perceived contradictions or 'gaps' (Ellis and Poole, 2014) between what creative arts education attempts to teach, how it is taught within the institution, and what graduates demonstrate within professional creative practice. Through a recognition and critique of these 'gaps', I question whether it is possible to actively work within these 'messy' spaces, to chase the ambiguities present, in order to foster sustainable dance graduates that can work more visibly alongside academics to shape the current dance landscape.
\end{abstract}

Keywords: ambiguity, gaps, student-centred learning, higher education, sustainable dance graduates, institutional structures

\section{Introduction}

Within this paper I would like to present a number of ideas surrounding dance pedagogy within higher education in the UK, specifically the impact that current university structures and pedagogical approaches have on the notion of producing 'sustainable dance graduates'. If, as Shreeve, Sims and Trowler $(2010,125)$ discuss, arts education should be concerned with 'uncertainty and open-endedness', I ask the question, are we able to foster this alongside current institutional demands and embedded pedagogies? If not, then what effect does this have on current dance graduates? To attend to these questions I frame my discussions around personal critical reflections upon two 
embodied roles, my role as a Senior Lecturer in Dance at Leeds Beckett University and my work as an artist choreographer.

Over the last three years I have been involved in several choreographic projects were I have worked with dance graduates from two higher education institutions, Leeds Beckett University and Hull School of Art and Design. These projects include a period of choreographic research as part of 'Thinking Dance', a practice-as-research event at Yorkshire Dance in 2014, the creation of new a choreographic work for the Hull Dance Prize in 2015, and a third period of choreographic research at Leeds Beckett University in the summer of 2016. The work explored and created on these projects centred on ideas of 'contamination', based on an exploration of Drew Leder's (1990) text 'The Absent Body', specifically his concepts of dys-function, dys-appearance and absence. Whilst I intend not to elaborate on this choreographic practice with much depth, I do acknowledge that the content of these explorations has had an impact on what is discussed here. Most notably, Leder's concept of 'dysfunction', which he also describes as 'problematic operations' (1990: 85), resonates with my later discussions on ambiguity as a creative space for pedagogical practice. Instead, this paper intends to focus upon the actual experience of working together with dance graduates on the aforementioned professional projects, and how such experiences prompted a need for critical reflection upon pedagogical practice and approaches within higher education.

For instance, during the summer of 2015, when working on a new choreographic work for the Hull Dance Prize, I experienced a very turbulent relationship with the dance graduates I was working with. Turbulence arose from a conflict between my own search for unpredictability and the graduates search for predictability, security, and order in their intersubjective relations and the choreographic material. The graduates demonstrated in studio practice an active resistance to disorder. This turbulence forced us to have to extend and intensify the making process and address our own responsibilities and behaviours within that process. It became a relationship fraught with anxieties about position, accountability, ownership, skill, and creativity. I use the term anxiety here, because drawing upon the work of Giddens (1991) I believe that the acknowledgement of my own anxiety during this particular creative project, of my 'notknowingness', what Giddens might describe as helplessness, posed a threat to the integrity to the graduates own security system $(1991,46)$. Particularly, to their knowledge and understanding of creative practice achieved through their degree programmes. It was this threat that began to make explicit apparent 'gaps' in my 
understanding of established pedagogical approaches, my application of them in practice, and their impact on dance graduates.

I recognise that many collaborative projects can be fraught with anxiety and conflict, Ellis and Poole (2014) in their work on collaboration and violence, would even suggest that collaboration prospers under conditions of antagonism. However, there was something more specific about the problems the graduates and I encountered when working together that began to transfer attention away from the choreographic work, the artistic practice, and back onto our previous relationship of working together within the institution. Firstly, I was uncomfortable with the relationship between the graduates and I, which kept being enforced by their need for order, structure and clear instructions at each step of the creative process. A traditional teacher - student hierarchy became recognisable in the way we were operating within the studio. My position became centred, with an expectation that I would transmit material, concept, and content (Biggs and Tang, 2011). Secondly, I felt pressured by their constant drive towards ends, finishing points, a job done, so to speak. Thirdly, what both these issues and other occurrences highlighted was their apparent 'fear' of ambiguity. The nature of the choreographic project I had established demanded ambiguity in relation to the strategies and vocabularies explored, for, in attempting to explore places of 'absence' we had to acknowledge what Leder terms the '...paradox of the present-absent body' (1990: 21). Yet, the graduates and I struggled to operate together within such spaces and consequently, tension, unrest, and hostility arose.

I acknowledge that part of this issue was certainly based around a moving away from our previous professional relationship, I had been their lecturer, I had guided and promoted learning, being the signifier of assessment, of measures of success perhaps. But there is more to this. Drawing on the work of Mike Neary and Andy Hagyard $(2010,2012)$ and their exploration of the concept of 'student as producer', which I elaborate on in later discussions, I would argue that the conventions associated with such a relationship, established by the current university environment, were being taken for granted by the graduates. In doing so, they were inadvertently assuming a natural attitude to the structures of creative practice, to their relationship with me in the creative space, by applying the same conventions.

\section{Pedagogical Considerations}


Through my experiences of working with dance graduates, it would appear then, and I suppose this sounds like common sense, that they continue to desire stability, they want to feel secure in the way they need to orientate themselves outside of the institution, within creative practice, so they can have what Giddens (1991: 37) describes as 'faith in the system'. Of course, as a pedagogue, I would like dance graduates to feel secure and have trust in their previous educational experiences. However, once institutional structures, and the reliability of persons is removed, it has been my direct experience that they struggle to find the approaches and the skills needed to manage professional transitions, crises, and circumstances of high risk that are needed in professional creative practice. I propose that perhaps one of the reasons why undergraduate students, and consequently graduates, have become so 'faithful' in the strict structuring of the higher education system, for example its compartmentalisation of content through modular approaches, and it's embedded hierarchies, is to do with the changing approach to and wider understanding of 'student centredness'.

For many pedagogues, teaching and learning within the 21 st century is embedded with a focus on independent study, problem-based learning, research-based teaching, as well as student-centred or led teaching and learning, which research tells us, enhances student engagement and achievement (Biggs and Tang, 2011; Neary, 2012). In my own teaching practice I have always attempted to adopt what Elen et al (2007) terms a 'transactional' approach to teaching and learning, where students and teachers are jointly responsible for the success of the learning process, a role that does not lie far from one of collaboration within choreographic projects (Butterworth, 2009). However, based on my experiences of working with dance graduates, on reflection, it would appear that within current institutional structures I have become more fearful of this approach and it is not fully embedded in my practice. This is particularly true when I think about the pressure I feel to adhere to the culture of 'educational transparency', where everything from the moment of planning must be outlined and made explicit to the students, so as to be accountable for the outcomes (Strathern, 2000: 310).

When I consider this, I begin to identify why the dance graduates I have worked with may struggle with ambiguity, because for myself ambiguity is already, even in my planning of teaching and learning, being suppressed. Suppressed through a process of 'transparency'. Suppressed, because as Strathern discusses, the institution has placed value on '...visibility as a conduit for knowledge' (2000: 310). I question then, as Neary 
and Winn (2009), Elen et al (2007) have, whether the pedagogical processes I aim to adopt in practice, such as student-centred learning, are in themselves becoming functionally enforced rather than radical? And what impact this then has on the creative practice undertaken with students and graduates? Of course, I do not want my pedagogies to overwhelm the students I work with, for trust is essential in building meaningful exchanges (Giddens, 1991: Carvalho and de Oliveira Mota, 2010), and we may assume transparency and structure are part of developing that trust in higher education. But, if pedagogy, shaped by institutional structures and educational transparency is equally a threat to the creativity and professional identity of dance graduates, what else can we put trust in?

Curzon-Hobson (2002) in his article 'A Pedagogy of Trust in Higher Learning' reflects upon a similar problem when discussing the relation between trust and risk. He critiques the premise that higher education institutions, and the student, can only develop trust when risk is minimised in the approach and work of the pedagogue, which may be checked by the institution through heavily embedded quality procedures and blanket pedagogical approaches. Instead Curzon-Hobson argues that 'freedom', as is synonymous with trust, can only be achieved with 'risk' at its centre. The student and teacher must firstly take a risk in trusting one another, but furthermore they must put trust in risk, in order to meaningfully operate in a 'world beyond absolutes' (2002: 266). In order for this idea to be embraced, Curzon-Hobson asks that the student and teacher reimagine their stance towards each other and the educational material, and I would argue, the institution.

Mike Neary $(2009,2010)$ and Joss Winn's (2009) research surrounding the concept of 'Student as Producer' addresses similar concerns. 'Student as Producer' is an approach to pedagogy that places 'research' at the centre of practice for both academics and students. The concept arose from Neary and Winn's concern with the way universities have allowed themselves to be redesigned according to the logic of market economics and business structures. In response to such discussions, Neary and Hagyard in their article 'Pedagogy of Excess' (2010), discuss the need to develop progressive, rather than functional relationships between academics and students by radicalising the relationship between teaching and research. They call for the need to address '....an alternative political economy of the student experience.' $(2011,1)$

In making a context for these discussions Neary and Hagyard introduce the reader to the Student Protests that took place in Paris in 1968. Whilst I do not wish to 
go into detail about this here, Neary and Hagyard, citing Ross (2002) state that one of the most significant moments of these protests was when the students involved, 'refused to act like students' (2011: 214). During the protests the students refused the behaviours that their current education was instilling in them. This becomes significant when we align this with research into the effectiveness of 'student-centred learning' approaches (Elen et al, 2007; Felder and Brent, 1996) and the particular behaviours and collective student identities that have begun to become synonymous with this approach. What many of the critiques of 'student centredness' unpack is the assumption of a collective 'student identity' that actually does not place the individual learner at the heart of learning/of practice. Instead as Neary, Hagyard and others discuss, current pedagogical agendas, and I would suggest this includes 'studentcentredness', have played into the hands of the controversial notion of 'student as consumer' (Neary and Hagyard, 2009; Boden and Epstein, 2006). With students selfidentifying with the position of a 'right to' do, which consequently leads them to '...rule curriculum content and styles of pedagogy...' (Boden and Epstein, 2006: 227).

Here, I am not suggesting a return to teacher-centred learning but rather a questioning of what would happen to dance pedagogy within higher education if neither role was thought to be centred? What would happen if we began to question such functional pedagogies and instead find time and space to discuss pedagogies, which, as Neary asserts, consider ways of '...problematising the relationship between teacher and student as to provide some critical context for the institutions within which students and academics are working - and a basis for their relationships within a social world' (Neary, 2012: 250). To further this point, it is perhaps important to recognise that Neary's 'Student as Producer' is based on a negative critique of the current university structure, with the specific dysfunctional structure explored being the 'gap' between research and teaching, which consequently creates a gap between academic and student. Neary aligns this discussion with Lawrence Lessig's (2004) work on 'Free Culture', which offers a critique of dominant cultures, which may restrict creativity. Within these discussions emphasis is placed on 'permission'. Creators, or in the context of these discussions students, get to create '...only with the permission of the powerful, or of creators from the past' (Lessig, 2004: xiv). When I reflect upon the process of working with dance graduates I might ask then, where was 'permission' aligned, or looked for? And, what affect was this having on our creative freedom when working collaboratively? 
Neary and Winn, suggest that if we begin to work with the students in the role of producer, and collaborate, remove 'permissions', this '...enables both students and academics to do more than restructure curricula and pedagogy, but to challenge the very organising principles upon which academic knowledge (and I would argue creative practice) is currently being [exchanged] and produced' (Neary \& Winn, 2009: 208). It is not simply about redesigning curriculum and pedagogical approaches but the principles and structures of knowledge exchange/production, and creative practice within the institution and how students, graduates, and academics may collectively contribute to that.

Like the premise of Neary's 'Student as Producer' (2010, 2012) and CurzonHobson's (2012) reimagining of 'trust', if we could find different ways of 'being' with our dance students, radical ways of producing curriculum and research together, we might begin to change the potential for creative practice within the institution and produce graduates who can work with us to make more significant changes to the sector at large. In order to achieve this Neary would put his trust in a collective pursuit of research, and Curzon-Hobson in 'risk'. However, I would like to propose that the conflicts and tensions that exist as a result of the ambiguous and sometimes turbulent relationships between teacher and student, creative practice, and institutional structures offer us a space to radicalise pedagogical practice.

In returning then to the choreographic projects outlined in the introduction to this paper, when working with dance graduates there were several 'dysfunctional' structures at work that were reflective of, if not enforced by, our previous experiences of working together within the institution. To reiterate these, an enforced hierarchy, a need for structure, transparency, all of which, by not being addressed within the creative process, but instead ignored, were causing problems for the choreographic work, our creative relationship, and our professional development. The turning point in the creative process of the second project, when making a work for the Hull Dance Prize, was my own conscious moment of resistance, of me saying, perhaps 'admitting' is a better word here, 'I don't know what this work is, I don't know where am I going, I don't know what this material is, I don't know what this material should feel like on your body, only you can tell me what this vocabulary is." This was the point when change began to occur. What this change involved was the recognition of a need for ambiguity and through this, the recognition and acknowledgment of 'gaps'. Gaps between their expectations, my expectations, our roles, our behaviours, and our 
perspectives. Gaps is a term I am borrowing here from the writing and practice of Simon Ellis and Colin Poole, (2014).

\section{'Gaps'}

Within the chapter 'Collaboration, Violence, and Difference', Ellis and Poole when discussing their collaboration on the choreographic work 'Because We Care' (2012) unveil, using Žižek's 'Parallax Gap' (2006), the violence that emerged in their making process together. They discuss how creativity was not found in the harmonious relationships that have become synonymous with what we might describe as the most 'effective' collaborative processes. Instead, they discuss their discovery and exploration of creativity that emerged as a result of the violence and the 'gaps' or blind spots between them, 'blind spots', they suggest '...that could only be revealed by someone or something else' (2014: 210). Within their collaboration, rather than ignoring moments of tension, unrest, aggression, they would confront these. Their process of operating within such gaps was messy, exposing, people were hurt, but ultimately an understanding of difference and its potentiality was learnt. As such, they use Žižek's Parallax Gap, defined by Žižek as '...the confrontation of two closely linked perspectives between which no neutral common ground is possible...' (2006:4), as a metaphor for two creative positions, which can never meet.

The context of Ellis and Poole's work is significantly different to my reflections here, theirs is based on conflicts that arose from an exploration of white and black masculine identities, whereas I am seeking to re-imagine pedagogical practice within higher educations institutions with dance students and graduates. However, it is their acknowledgement of the learning that occurred as a consequence of operating in ambiguous spaces, in gaps, that is significant. Ellis and Poole do not attempt to build a 'harmonious' bridge over the ambiguous, messy gaps that appear in their collaboration together. Instead they encourage us to attempt to operate within that space, to have our blind spots revealed so that learning can occur and creativity can be fostered. As such, their words and reflections have been useful to me in making sense of, and in beginning to think differently about how I might work towards a radical pedagogy, which operates within the 'gaps' between teacher and student, creative practice, and institutional structures, where at times, there appears to be no common ground to differing perspectives (Žižek, 2006:4). In order to achieve this, what their work teaches me in the 
first instance is to stop being 'faithful' to either the demands of the institution or those of creative practice. Instead it encourages me to embrace the 'fear' of the gap between my own pedagogy, my artistic practice and the structures that surround it. It is about placing faith in my fear of those gaps in order to move my pedagogy forward.

Within the creative process for the Hull Dance work once these 'gaps' were acknowledged, and I appreciate their is a slight contradiction here, then the choreography began to be born of the ambiguities and dysfunctional relationships present, not in spite of them. We used the points of tension that arose when operating within ambiguous spaces to create the work. We held stillness' a little too long, chose a sound score of a womb that never changed apart from in volume, we placed our hands and heads into places that are normally seen as private, we chased absence in the body, and found pleasure in dys-comfort. I could never demonstrate to the graduates the choreographic material or describe it to them, all I could do was try to make them uncomfortable within their own body, to offer ambiguous strategies and tasks, and of course, as soon as the choreography was comfortable, that wasn't the choreography anymore.

Following this project I was left questioning, how I could embrace such ambiguity within my pedagogical role at Leeds Beckett University? When I reflect upon my current pedagogical practice it's not that ambiguity or 'gaps' don't exist, but it is easy, for example, to say to students when ambiguity presents itself in teaching and learning that, 'it's fine', 'it's ok', 'don't worry you'll understand it later', or perhaps worse 'it's ok not to understand'. When actually, all this does is smooth over the gaps so ambiguity stops being real for those students. They don't experience the gaps. Should we instead be saying 'yes you should be fearful but how are you going to deal with that?' I propose that many pedagogues, including myself, have developed ways of dealing with these situations in order protect ourselves. We become concerned that the student will think we don't know what we are doing, what we are talking about, that we can't help them. Perhaps this is because we don't want a low National Student Survey (NSS) score, or because we need our Key Performance Indicators (KPI's) to match the universities targets. All this feeds into what Bonfiglio (2015) describes as a kind of 'institutional anxiety', reinforced by institutional pressures, brought on by educational transparency, as well as the pressures placed on academics by students themselves. The way then we try to fill gaps within our pedagogical practice is through concepts of ambiguity, rather than ambiguity itself. 
As artists, choreographers, creative pedagogues surely it is these gaps that we should be chasing? Yet my understanding, based on my experiences of working with recent graduates is that the pedagogy that exists within the current higher education environment cannot risk such gaps. Hence, we fall into a habit of filling them in order to keep the student content. At least, this is how I find myself operating within the regulations, the policies, the bureaucracy, and the metrics I am often then measured against. However, I understand that to reject the university system altogether, to say that dance cannot exist within the structures of the academy is simply to reverse the binary, again to close down gaps and ambiguities. I suggest it would be better for us to dive in and explore the ambiguities. To embrace, chase and attempt to operate within the gaps many of us do feel anxious about between artistic practice, institutional structures, wider institutional metrics, research cultures, pedagogy, and our students.

\section{Sustainable Dance Graduates}

Following a sharing of work on the first project 'Thinking Dance' in 2014 one of the first points of feedback I received from a fellow colleague was that "I should be working with professional dancers". At the time, this specific piece of feedback really struck a chord with me for, in my choice of dancers I had not really considered their role as recent graduates and the significance of this on the research or choreographic material produced. I questioned, did working with graduates alter the process, what did it bring to the process, and what did it tell me about these young dance artists? It was a comment that initially forced me to question my decision to work with recent dance graduates. I do not however, wish to critique here the impact that professional dancers verses graduate dancers might have on choreographic work or research being produced. Instead, what is of interest to me, is that in moving outside of the institution to work with these dance graduates, the experiences that occurred forced me back into reflecting upon the pedagogy that directly influences their transition from the institution into the professional world.

In returning then to the premise of this paper I ask, what does it mean to produce sustainable dance graduates? How is the current higher education environment preparing dance graduates to deal with the ambiguous spaces I am suggesting we operate within? There is much research into postgraduate dance companies and their role in transitioning dance students from undergraduate to professional and similarly, 
there is much research centred on the importance of instilling graduate attributes such as employability skills, entrepreneurship, global outlook, and digital literacy within arts students (Hunter and Gladstone, 2009; Daniel and Daniel, 2013; Bennett, 2016). But, what about behaviours, values and modes of being that encourage dance graduates to consider their own 'sustainability' in a complex and ambiguous world?

Based on my experiences of working at Leeds Beckett University and as an artist choreographer I believe higher education is producing graduate students that understand the concepts of ambiguity that are explored here, but they are not equipped with the behaviours, values, and abilities to experience them in practice. The projects mentioned here were originally intended as practice based research projects, however, through the process of working with graduates, it has made evident to me that what students seem to struggle with is the practicing of ambiguity. Furthermore, the functionality of the pedagogies I employ in my role as a senior lecturer do not support students in achieving the 'uncertainty' of professional creative practice advocated by academics such as Shreeve, Sims, and Trowler $(2010,125)$.

\section{Conclusion}

Whilst my experience and research has not led me into a position to be able to offer such a thing as a model for radical pedagogy with regards to dance education within higher education, I am not even sure a model would be useful, what I do wish to do is identify certain points of significance. On each of the projects mentioned in this paper there were particular moments, situations, when the dance graduates and I found a different way of being with each other, when the work we were making evolved from the ambiguity present, when we recognised and found pleasure in the 'gap' between us. The graduates and I were stimulated by the same questions, but it was important that each of us approached these questions from different positions and gave each other license to disagree. This was difficult when the traditional teacher-student hierarchy was acting, but once we attend to this relationship our 'blind-spots' were revealed to us. As a consequence, we did not rely on any single person's previous training, technique, skills, or conceptual understandings, in fact we constantly, through a process of 'dysfunction' work against this. We were all equally responsible for the project, the choreographic material, the creative process. This new relationship, that both the graduates and I were part of, was based on the construction and recognition of 'gaps' 
between self and other and as such, nobody could speak on behalf of the other. Not even in my role as choreographer, as the person establishing the work, could I take control over the creative process because there was a sense of the work only being able to be felt, language was addressed as a barrier. Due to all of this, we had to actively work with conflict and ambiguity. We chased ambiguity in the studio, in the choreographic material, and in our relationship to one another by de-centring each of our roles.

The challenge now is to apply the outcomes of this research, the 'ways of being' expressed here, in my work with undergraduate students. In doing so I hope to challenge the functionality of my current pedagogical approaches and address the innate fears that have developed in working creatively in institutional structures. In line with what Eisner (2008) discusses with reference to Arts-Informed research, what is discussed here is intended to generate significant questions that need addressing, rather than provide answers, because I wish to remain sensitive to the complex subtleties of the subject matter. As such, I am not interested in providing watertight conclusions about how to make our graduates forge sustainable professional careers, but rather offer my own experiences as a way of problematising the institutional rhetoric of dance in higher education. In this sense, and as Eisner notes, I would like to invite the potential for deep conversation and insightful dialogue rather than 'error-free conclusions' (2008: 7).

On this point I would like to finish by drawing on the words of Walter Benjamin (as cited in Eiland, 2011) and ask How do we secure an environment for dance education that is 'grounded in the productivity of its students', its graduates, as well as academics? What might this do to the landscape of dance and creative practice happening within higher education institutions? What might it do to challenge the structures that work to suppress the ambiguity that is discussed here? Furthermore, how can ambiguous creative practice inform and feed into ideas of knowledge production, exchange, generation, new pedagogies, and the shape of higher education. In addressing these, can we do more to produce graduates who can work with us to secure and evolve an exciting dance landscape and future professional practice, through a process of chasing ambiguity? 


\section{References}

Benjamin, Walter. 2011. "The Life of Students", In Early Writings (1910-1917) Walter Benjamin, edited by Howard Eiland. London: Harvard University Press.

Bennett, Dawn. 2016. "Developing Employability and Professional Identity Through Visual Narratives.” Australian Art Education 37 (2): 100-115. ISSN: 10321942

Biggs, John and Catherine Tang. 2011. Teaching for Quality Learning at University. Berkshire: Open University Press

Boden, Rebecca, and Debbie Epstein. 2006. "Managing The Research Imagination? Globalisation And Research In Higher Education." Globalisation, Societies and Education 4 (2): 223-236. doi: 10.1080/14767720600752619

Bonfiglio, Robert. A. 2015. "High Anxiety in Higher Education." About Campus. Advanced Online Publication: 27 - 30. doi: 10.1002/abc.21196

Butterworth, Jo. 2009. "Too Many Cooks? A Framework for Dance Making and Devising." In Contemporary Choreography: A Critical Reader, edited by Jo Butterworth and Liesbeth Wildschut, 177-194. Oxon: Routledge.

Cabral, Ivam and Rodolfo García Vázquez. 2016. “A Brazilian Pedagogical Project for the Teaching of the Arts in the Twenty-First Century." Theatre, Dance and Performance Training, 7 (1): 89-105. doi: 10.1080/19443927.2015.1133444.

Carvalho, Sergio W, and Márcio de Oliveira Mota, 2010. "The Role of Trust in creating Value and Student Loyalty in relational Exchanges Between Higher Education Institutions and their Students." Journal of Marketing for Higher Education 20 (1): 145165. doi 10.1080/08841241003788201.

Curzon-Hobson, Aidan. 2002. "A Pedagogy of Trust in Higher Learning." Teaching in Higher Education 7(3): 265-276. doi: 10.1080/13562510220144770 
Daniel, Ryan, and Leah Daniel. 2013. "Enhancing the Transition from Study to Work: Reflections on the Value and Impact of Internships in the Creative and Performing Arts." Arts and Humanities in Higher Education 12 (2-3): 138153. doi: $10.1177 / 1474022212473525$

Eisner, Elliot. 2008. "Art and Knowledge" In Handbook of the Arts in Qualitative Research: Perspectives, Methodologies, Examples and Issues, edited by J. Gary Knowles and Ardra L. Cole, 3-12. London: Sage Publications Ltd.

Elen, Jan, Geraldine Clarebout, Rebecca Leonard, and Joost Lowyck. 2007. "Studentcentred and Teacher-centred Learning Environments: What Students Think." Teaching in Higher Education 12 (1): 105-117. doi: 10.1080/13562510601102339

Ellis, Simon and Colin Poole. 2014. "Collaboration, Violence and Difference”. In Žižek and Performance edited by Broderick Chow and Alex Mangold, 209-223. Hampshire: Palgrave Macmillan.

Felder, Richard M, and Rebecca Brent. 1996. "Navigating the Bumpy Road to Student Centered Instruction." College Teaching 44 (2): 43-47.

Giddens, A. 1991. Modernity and Self-identity: Self and Society in the Late Modern Age. Stanford: Stanford University Press.

Hunter, Victoria and Pauline Gladstone. 2009. "Dance and Social Inclusion: Facilitating the Process, Developing Graduate Employability." The Journal of the Arts in Society 4 (2): 149-160. ISSN 1833-1866

Leder, D. 1990. The Absent Body. Chicago: University of Chicago Press.

Lessig, Lawrence. 2004. Free Culture: The Nature and Future of Creativity. London: Penguin Books

Neary, Mike. 2010. "Student as Producer: a pedagogy for the avant-garde?" Learning Exchange, 1 (1). ISSN UNSPECIFIED 
Neary, Mike. 2012. "Teaching Politically: Policy, Pedagogy and the New European University." Journal for Critical Education Policy Studies, 10 (2): 233-257. ISSN $1740-2743$

Neary, Mike and Joss Winn. 2009. "The Student as Producer: Reinventing the Student Experience in Higher Education" In The Future of Higher Education: Policy, Pedagogy and the Student Experience, edited by Les Bell, Howard Stevenson, and Mike Neary, 126-138. London: Continuum.

Neary, Mike and Andy Hagyard. 2010. "Pedagogy of Excess: An Alternative Political Economy of Student Life" In The Marketisation of Higher Education and the Student as Consumer, edited by Mike Molesworth, Richard Scullion, and Elizabeth Nixon, 209: 223. Oxon: Routledge

O’Neill, Geraldine, and Tim McMahon. 2005. "Student-centred learning: What does it mean for students and lecturers," Emerging Issues in the Practice of University Learning and Teaching Online Publication: URL http://www.aishe.org/readings/20051/oneill-momahon-Tues 19th_Oct SCL.html

Ross, Kristin. 2002. May '68 and Its Afterlives. Chicago: University of Chicago Press Shreeve, Alison, Ellen Sims, and Paul Trowler. 2010. “A Kind of Exchange: Learning From Art and Design Teaching", Higher Education Research and Development 29 (2): 125-138. doi: 10.1080/07294360903384296

Strathern, Marilyn. 2000. "The Tyranny of Transparency", British Educational Research Journal 26 (3): 309-321. doi: 10.1080/713651562

Žižek, Slavoj. 2006. The Parallax View. Massachusetts: The MIT Press 